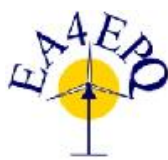

International Conference on Renewable Energies and Power Quality (ICREPQ'13)

Bilbao (Spain), 20 ${ }^{\text {th }}$ to $22^{\text {th }}$ March, 2013

Renewable Energy and Power Quality. Tournal (RE\&PQJ)

ISSN 2172-038 X, No.11, March 2013

\title{
Control strategy to improve the power factor with a hybrid filter
}

\author{
Salvador P. Litrán, Patricio Salmerón, Alejandro Pérez Vallés \\ Departamento de Ingeniería Eléctrica y Térmica \\ Escuela Técnica Superior de Ingeniería, Huelva University \\ Ctra. de Palos de la Frontera s/n, 21819, Palos de la Frontera, Huelva, Spain \\ Phone: +34-959217585, Fax: +34-959217304 \\ e-mail: salvador@uhu.es; patricio@uhu.es; aperez@uhu.es
}

\begin{abstract}
Nowadays an electrical system must provide adequate electrical power quality so that it meets the international standards. To do this, this paper develops a control strategy for an active compensator based on a hybrid filter topology. This topology is formed by an active power filter of series connection and a passive filter of parallel connection. The proposed strategy is based on minimizing the rms value of the voltage at the point of common coupling so that the source transfers the power demanded by the load. Thus, the determination of the reference signal is posed as a constrained optimization problem. The strategy was proposed for four-wire systems and it allowed the compensation of current harmonics, reactive power and neutral current. Finally, a simulation platform in Matlab-Simulink was developed. This allowed the verification of the new strategy for different types of loads.
\end{abstract}

\section{Key words}

Harmonics, electric power quality, active filter, hybrid filter.

\section{Introduction}

In recent decades, the concept of Power Quality (PQ) has gained notoriety in the field of Electrical Engineering. So, today it has become a matter of great interest to production and distribution companies of electricity and end users.

Different solutions for improving the quality of power have been proposed. Some of them are based on passive filters, which can be understood as devices that change its impedance as a function of frequency. Others are based on active filters, which are able of compensating harmonics of the network with power electronic converters. These filters can be connected in parallel or in series, depending on the load type to compensate [1], [2]. Also, the combination of both filter kinds (active and passive) is possible, forming what is known as hybrid filter. Here, the active filter contributes in improving the frequency response of the passive filter.

One of these hybrid filter topologies is based on an active filter in series with the source and a passive filter in parallel with the load [3]-[5]. This configuration improves the behaviour of the passive filter, which tuned to the appropriate frequency achieves the harmonics elimination of the source current with a consequent enhancement of signal quality.

Various control strategies have been tested for the active filter where the main aim is to improve the filtering characteristics of the passive filter. For this purpose a common strategy is to generate a voltage proportional to the source current harmonics [3], [4] in the active filter. In this way, it is achieved that the active filter presents high impedance to the harmonics of the load current. This improves the behaviour of the passive filter, so that, on the one hand it prevents possible resonances and on the other hand it make that the filtering characteristic of the passive filter is independent of the impedance source.

In another strategy the active filter generates a voltage equal to the load voltage harmonics but of opposite sign, however, it is unable to avoid the disadvantages of passive filters. More recently, it has been proposed a hybrid strategy that combines the previous two strategies [6], which improves the filtering features of the two previous strategies.

On the other hand, others strategy proposals suggest that the active filter generates a voltage so that it compensates the reactive power load and passive filter and eliminates current harmonics $[7,8]$. The calculation algorithm is based on the formulation of the instantaneous reactive power [9], [10] in order to achieve constant power on the side source when it is applied to balanced, three-phase and three-wire system.

Similar compensation objectives are proposed in [11], [12] where the control strategy is based on the dual vectorial formulation of the instantaneous reactive power. This strategy is applicable to unbalanced, three-phase, four-wire systems and it allows the reactive power can be compensated and the source current harmonics to be eliminated.

This paper develops a control strategy for a hybrid filter composed of an active power filter of series connection and a passive filter of parallel connection. The strategy 
proposal is based on minimizing the effective value of the voltage at the point of common coupling (PCC) to ensure the power transference demanded by the load.

Thus, the determination of the reference signal is raised as a problem of constrained optimization to systems of four wires. This allows the harmonic mitigation, the reactive power compensation and the neutral current elimination.

The proposed strategy was applied to a model of hybrid filter based on Matlab-Simulink. Simluation results have allowed the verification of their performance in the compensation of nonlinear loads of four wires.

\section{Control strategy for hybrid compensator}

This section presents a compensation method based on the average value. The aim is to determine the minimum rms value of the voltage at the PCC (Point of Common Coupling) so that the system transfers the active power to the load. To develop this strategy a polyphase system is considered as a special case of multiconductor system [13]. Thus, a four-wire three-phase system can be represented by means of a multiconductor system as Fig 1 shows.

The currents $i_{1}, i_{2}, i_{3}$ and $i_{4}$ are the components of the line current vector, which is defined by

$$
\mathbf{i}=\left[\begin{array}{llll}
i_{1} & i_{2} & i_{3} & i_{4}
\end{array}\right]^{T}
$$

As a consequence of Kirchhoff's current law, for the current vector, $\mathbf{i}$, is satisfied that

$$
\left[\begin{array}{llll}
1 & 1 & 1 & 1
\end{array}\right]\left[\begin{array}{llll}
i_{1} & i_{2} & i_{3} & i_{4}
\end{array}\right]^{T}=0
$$

Therefore, one of the components can always be expressed as a linear combination of the others. From the mathematical point of view, only 4-1 components are sufficient to describe the current vector. However, in fourwire three-phase systems the use of the four current components permits a direct description of the system behaviour.

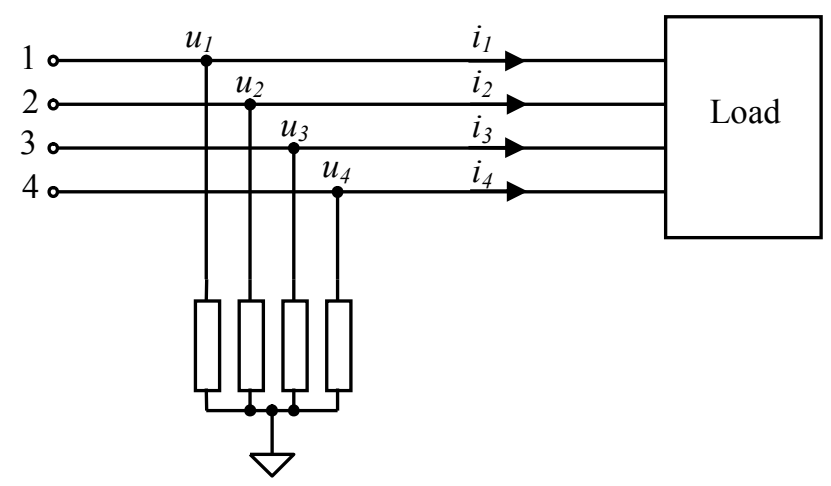

Fig. 1. Four wires system

The system voltages may be defined with respect to a virtual neutral point. This corresponds to the neutral of a star formed by four impedances of the same value, as it is shown in Fig 1.

In this way, it is possible to define the voltages, $u_{1}, u_{2}, u_{3}$ and $u_{4}$ of each wire with respect to this common point.
These voltages are the components of the voltage vector, $\mathbf{u}$, which is defined by means of

$$
\mathbf{u}=\left[\begin{array}{llll}
u_{1} & u_{2} & u_{3} & u_{4}
\end{array}\right]^{T}
$$

The four components of the voltage vector must verify that

$$
\left[\begin{array}{llll}
1 & 1 & 1 & 1
\end{array}\right]\left[\begin{array}{llll}
u_{1} & u_{2} & u_{3} & u_{4}
\end{array}\right]^{T}=0
$$

In what follows, the subscript $\sum$ is used to refer to these "collective" values, including the fourth wire.

For a four-wire system the instantaneous power is obtained by the scalar product of the voltage vector by the current vector which is expressed by the equation

$$
p_{\Sigma}=\mathbf{u}^{T} \cdot \mathbf{i}
$$

In steady state and periodic conditions, the average value of the instantaneous active power and rms value of voltage vector and vector currents are defined for a fundamental period, $\mathrm{T}$. Thus, in regular conditions for an observation interval, $\mathrm{T}$, corresponding to one period or a multiple of the period, the root mean square or rms value is given by

$$
U_{\Sigma}=\sqrt{\overline{\|\mathbf{u}\|^{2}}}=\sqrt{\frac{1}{T} \int_{t}^{t+T}\left(\sum_{j=1}^{4} u_{j}^{2}\right) d t}=\sqrt{\sum_{j=1}^{4} U_{j}^{2}}
$$

Here, $U_{j}$ is the rms value of the $\mathrm{j}$ component of the voltage vector. In the same way, for the current vector given in (1) the root mean square value is defined by

$$
I_{\Sigma}=\sqrt{\overline{\|\mathbf{i}\|^{2}}}=\sqrt{\frac{1}{T} \int_{t}^{t+T}\left(\sum_{j=1}^{4} i_{j}^{2}\right) d t}=\sqrt{\sum_{j=1}^{4} I_{j}^{2}}
$$

Where $I_{j}$ is the rms value of the $\mathrm{j}$ component of the current vector.

The active power is obtained when the average value of the instantaneous power given in (5) is determined. Thus, for the fundamental period $\mathrm{T}$, the active power is given by

$$
P_{\Sigma}=\frac{1}{T} \int_{t}^{t+T} p_{\Sigma} d t
$$

From the compensation point of view with a series APF (Active Power Filter), the aim is the optimization of the average power transferred from source to load. For this, the voltage vector, $\mathbf{u}$, is determined such that its minimum rms value permits the power transference. To solve this optimization problem the technique of Lagrange multipliers is used. So, objective function is defined by

$$
F=\frac{1}{T} \int_{t}^{t+T} \mathbf{u} \cdot \mathbf{u} d t
$$

Subject to the constraint

$$
G=\frac{1}{T} \int_{t}^{t+T} \mathbf{u} \cdot \mathbf{i} d t=P_{\Sigma}
$$


With $F$ and $G$ functions defined in (9) and (10), Lagrangian equation is expressed as

$$
L=F+\lambda G
$$

Applying

$$
\begin{aligned}
& \frac{\partial L}{\partial \mathbf{u}}=0 \\
& \frac{\partial L}{\partial \lambda}=0
\end{aligned}
$$

The result is an equation system whose solution is

$$
\mathbf{u}=R \cdot \mathbf{i}
$$

Where $R$ is given by the ratio between the average power and the rot mean square value of the current

$$
R=\frac{P_{\Sigma}}{I_{\Sigma}^{2}}
$$

Here, $R$ represents the value of a resistive three phase load, which transfers the same active power that the load. The application of (13) allows the determination of voltage vector, $\mathbf{u}$. These voltages applied to a symmetrical resistive load of resistance $R$ transfers the same average power that the load to compensate. In this way, it is achieved that from the point of common coupling the system presents a unity power factor.

Fig. 2 shows a system of four wires compensated by means of a series active power filter. This is represented by four controlled voltage sources with values $u_{C l}, u_{C 2}$, $u_{C 3}$ and $u_{C 4}$. These four components make up the compensation voltage vector defined by

$$
\mathbf{u}=\left[\begin{array}{llll}
u_{C 1} & u_{C 2} & u_{C 3} & u_{C 4}
\end{array}\right]^{T}
$$

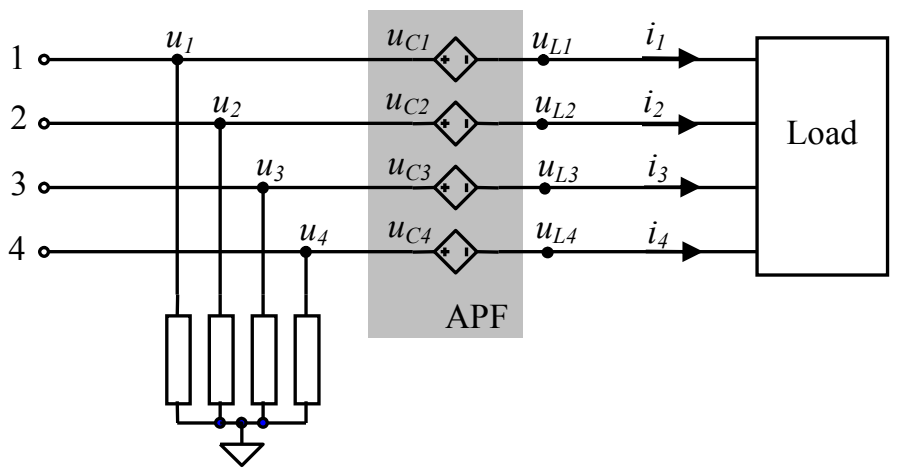

Fig. 2. Four wire system with series compensation equipment

When Kirchhoff's voltage law is applied to the circuit of Fig. 2, it provides for compensation voltage, $\mathbf{u}_{\mathbf{C}}$, the relationship

$$
\mathbf{u}_{C}=\mathbf{u}-\mathbf{u}_{L}
$$

Where $\mathbf{u}_{L}$ is the load voltage vector. Taking in account equations (13) and (14) it result

$$
\mathbf{u}_{C}=\frac{P_{\Sigma}}{I_{\Sigma}^{2}} \mathbf{i}-\mathbf{u}_{L}
$$

Furthermore, it is possible to obtain the average power transferred by the compensator. For this purpose, the expression (17) is multiplied by the current vector. If the resulting expression is integrated over the $\mathrm{T}$ period, the system power balance is obtained, this is

$$
\frac{1}{T} \int_{t}^{t+T} \mathbf{u}_{C} \cdot \mathbf{i} d t=\frac{1}{T} \int_{t}^{t+T} \frac{P_{\Sigma}}{I_{\Sigma}^{2}} \mathbf{i} \cdot \mathbf{i} d t-\frac{1}{T} \int_{t}^{t+T} \mathbf{u}_{L} \cdot \mathbf{i} d t
$$

The first term is the average power of the compensator, so that (18) can be rewritten as

$$
P_{C \Sigma}=\frac{1}{T} \int_{t}^{t+T} \frac{P_{\Sigma}}{I_{\Sigma}^{2}} \mathbf{i} \cdot \mathbf{i} d t-\frac{1}{T} \int_{t}^{t+T} \mathbf{u}_{L} \cdot \mathbf{i} d t
$$

The first term in (19) constitutes the active power consumed by the resistor $R$ and the second term the load average power, $P_{L \Sigma}$, which can be expressed by

$$
P_{C \Sigma}=\frac{P_{\Sigma}}{I_{\Sigma}^{2}} \frac{1}{T} \int_{t}^{t+T} \mathbf{i} \cdot \mathbf{i} d t-P_{L \Sigma}
$$

Considering the expressions (7) and (14), equation (20) can be set as

$$
P_{C \Sigma}=R I_{\Sigma}^{2}-P_{L \Sigma}=P_{\Sigma}-P_{L \Sigma}
$$

The expression (21) represents the power balance of the compensated system. The average power transferred by the compensator must be zero, then

$$
P_{\Sigma}=P_{L \Sigma}
$$

The equality (22) allows the numerator of (14) to be identified as the average power load

$$
R=\frac{P_{L \Sigma}}{I_{\Sigma}^{2}}
$$

Thus, the compensation voltage vector defined in (17) must be expressed in terms of the average power of the load, this is

$$
\mathbf{u}_{C}=\frac{P_{L \Sigma}}{I_{\Sigma}^{2}} \mathbf{i}-\mathbf{u}_{L}
$$

On the other hand, the application of equation (24) requires an inverter of four branches for four-wire systems. The use of this type of configuration has a higher cost and an added complication in the control circuit. In what follows, a simplification of the control strategy will be carried out, allowing the use of a three branches converter.

The compensation strategy defined by (24) is based on the set APF-load behaves as a symmetrical resistive load $(R)$ as it is shown in Fig 3. The set of four resistors connected in star represents the optimum load. This load has the same structure and the same voltage set that the load connected in star which defines the virtual neutral in Fig 2.

Moreover, an unbalanced nonlinear load can be represented by means of three nonlinear branches connected between phase and neutral as Fig 4a shows. In 
this figure, according to (24) the following equations are obtained

$$
\begin{gathered}
u_{C 1}=\frac{P_{L \Sigma}}{I_{\Sigma}^{2}} i_{1}-u_{L 1} \\
\vdots \\
u_{C 4}=\frac{P_{L \Sigma}}{I_{\Sigma}^{2}} i_{4}-u_{L 4}
\end{gathered}
$$

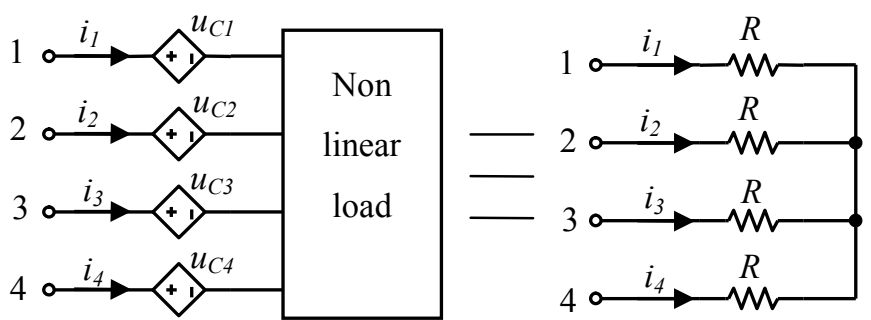

Fig. 3. Behaviour resistive of series APF and load

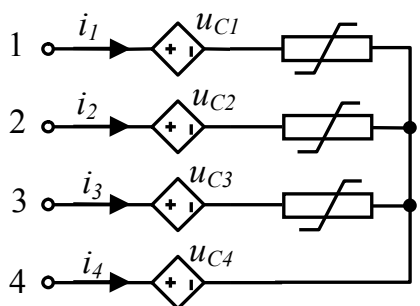

a)

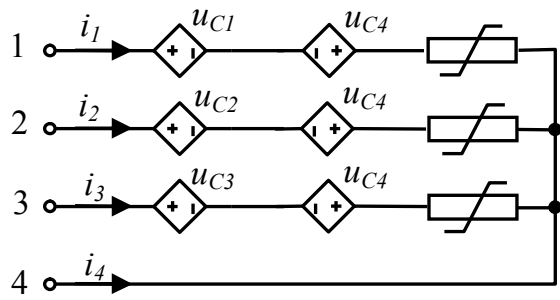

b)

Fig. 4. Correction of the compensation voltage when $i_{4} \neq 0$

When the source $u_{C 4}$ is displaced to the branches 1, 2 and 3 , the scheme shown in Fig. $4 \mathrm{~b}$ is obtained. Then, the compensation voltage can be determined by

$$
\begin{aligned}
& u_{C 1}^{\prime}=u_{C 1}-u_{C 4}=\frac{P_{L \Sigma}}{I_{\Sigma}^{2}}\left(i_{1}-i_{4}\right)-u_{L 4} \\
& u_{C 2}^{\prime}=u_{C 2}-u_{C 4}=\frac{P_{L \Sigma}}{I_{\Sigma}^{2}}\left(i_{2}-i_{4}\right)-u_{L 4} \\
& u_{C 3}^{\prime}=u_{C 3}-u_{C 4}=\frac{P_{L \Sigma}}{I_{\Sigma}^{2}}\left(i_{3}-i_{4}\right)-u_{L 4}
\end{aligned}
$$

Thus the expressions (26) allow determining compensation voltages for an active power filter constituted by three branches for any situation of the supply voltage.

\section{Simulation results}

The strategy control performance was verified in Matlab-
Simulink. Fig. 5 shows the circuit what was modeled. The load was nonlinear and it was constituted by three single phase rectified connected between phase and neutral wire. Each rectifier had connected at the dc side a inductor of $55 \mathrm{mH}$ in series with a resistor of $12.5 \Omega$. This load was compensated by a hybrid filter formed by an active power filter connected in series with the source and a passive filter connected in parallel with the load. The passive filter was constituted by two LC branches tuned at the harmonics of $5^{\text {th }}$ and $7^{\text {th }}$ order. The $5^{\text {th }}$ harmonic branch had a reactor with $13.5 \mathrm{mH}$ inductance and $2.1 \Omega$ resistance with a capacitor in series of $30 \mu \mathrm{F}$. The branch tuned at $7^{\text {th }}$ harmonic had $6.75 \mathrm{mH}$ inductance, $1.1 \Omega$ resistance and $30 \mu \mathrm{F}$ capacitance. At the output of the active filter was connected a ripple filter with $0.15 \mathrm{mH}$ inductance and a capacitor of $50 \mu \mathrm{F}$. The inverter had connected at the dc side two voltage source of $100 \mathrm{~V}$. The set inverter and ripple filter was matched to the power system by means of three single-phase transformers with a turn ratio of $1: 1$ to ensure galvanic isolation. The power circuit was connected to a sinusoidal, balanced, three-phase, $100 \mathrm{~V}$ source and 50 $\mathrm{Hz}$ frequency with a source inductance of $1.8 \mathrm{mH}$ and a source resistance of $1.4 \Omega$.

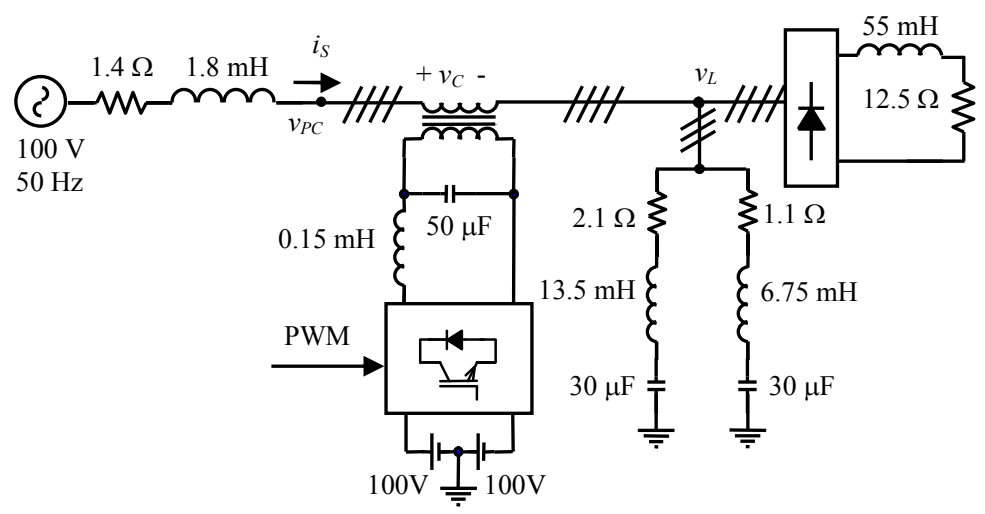

Fig. 5. Power circuit

Before active and passive filter connection, the voltage at the PCC and the source current had the waveforms shown in Fig. 6. The load active power was $1474 \mathrm{~W}$ and the power factor of 0.90 . The voltage at the PCC had an rms value of $88.6 \mathrm{~V}$ and a THD of $8.9 \%$. The most important harmonics were odd, being the higher rms value the $3^{\text {rd }}$ harmonic with $4.6 \mathrm{~V}$.

The source current had a THD of $27.7 \%$ with an rms value of $6.1 \mathrm{~A}$. The fundamental harmonic had an rms value of $5.9 \mathrm{~A}$. The most significative harmonic was the $3^{\text {rd }}$ with an rms value of $1.3 \mathrm{~A}$.

On the other hand, the neutral current presented an rms value of $4.0 \mathrm{~A}$. The load and source voltage were balanced, however, this value of the neutral current was due to the presence of homopolar sequence harmonics in the load current. The $3^{\text {rd }}$ harmonic had an rms value of 3.85 A. Fig. 9a shows the waveform of the neutral current before the compensation. 


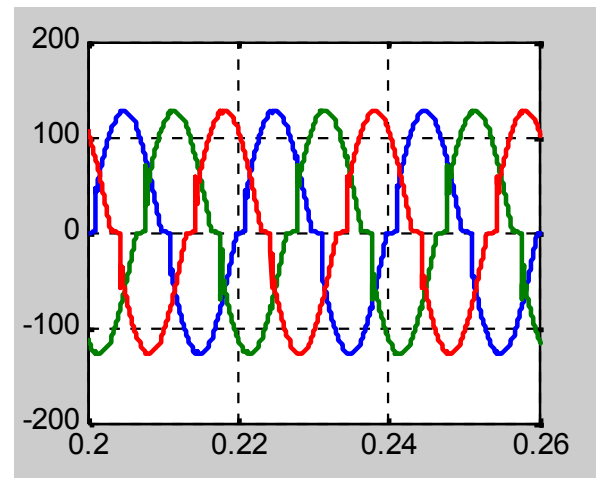

a)

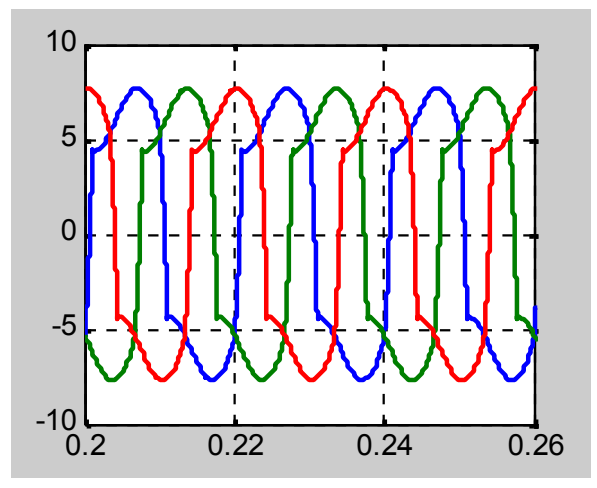

b)

Fig. 6. Waveforms before compensation: a) voltage at the PCC; b) source current

Subsequently, the active and passive filters were connected applying the proposed strategy. To determine the reference voltage of the active filter, the control scheme shown in Fig 7 was used. Input signals were phase voltage vector measured at the load side and the source current vector whose components were the three line currents. Transpose load voltage vector multiplied by the source current vector allowed the instantaneous power to be determined. Power average value was determined with a low pass filter (LPF). On the other hand, the rms value of the current vector components were calculated, squared and added. The fourth component of the current vector was obtained from the addition of the instantaneous values of the three components of the source current vector. Its value squared was added to the rms values squared of the source current vector components, it allowed the obtaining of $I_{\Sigma}^{2}$. This result together with the average power let determine the equivalent resistance $R_{e}$. On the other hand, the component $i_{4}$ was subtracted to the current vector components. The result was multiplied by the equivalent resistance, thereby the first term of (26) was determined, it was denoted as $\mathbf{V}_{\mathbf{P C}}$ in Fig.7. Finally, the compensation voltage was obtained as the subtraction between $\mathbf{v}_{\mathbf{P C}}$ voltage vector and the load voltage vector.

The compensation equipment together with the load had a power factor of 0.99 and an active power of $1570 \mathrm{~W}$. This power is slightly higher than the system without compensating $(1474 \mathrm{~W})$. It is due to the resistances used to model the inductances of the LC branchs. The voltage waveforms at the PCC are shown in Fig. 8a. Its rms value was of $89.3 \mathrm{~V}$ and its THD was of $0.42 \%$. Fig. $8 \mathrm{~b}$ shows the source current waveforms. Its rms value was of 5.88 $\mathrm{A}$ and its THD value of $0.59 \%$.

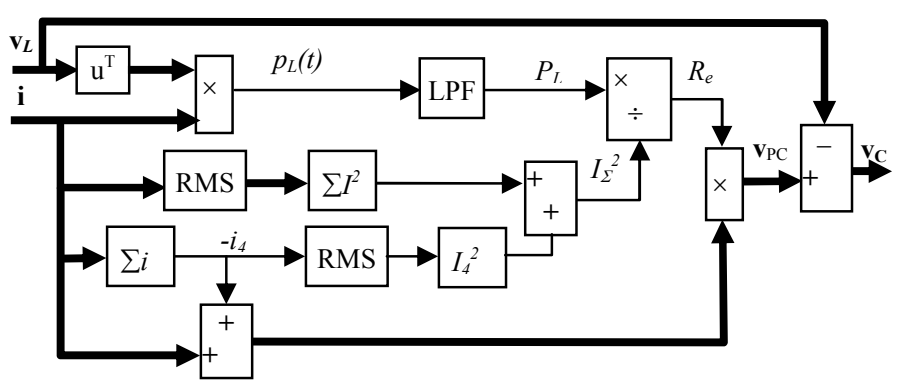

Fig. 7. Block scheme to determine the compensation voltage

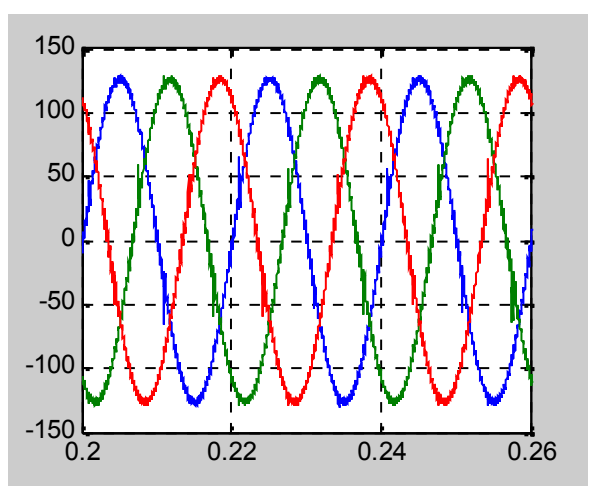

a)

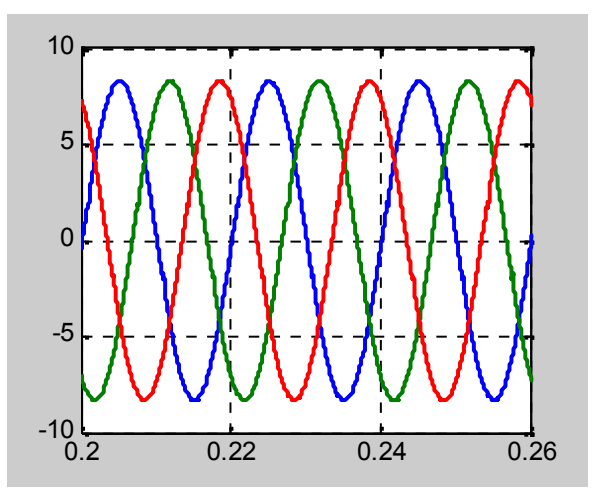

b)

Fig. 8. Waveforms after compensation: a) voltage at the PCC; b) source current

The neutral current had an rms value almost zero, $0.06 \mathrm{~A}$. Fig. $9 \mathrm{~b}$ shows the waveform after the compensation.

Therefore, when the load is balanced and has homopolar sequence components of the current, the proposed strategy makes the set load-compensation equipment work with unity power factor. Moreover, the source current and the voltage at the point of common coupling are practically sinusoidal. Finally, after the compensation 
the neutral current is practically zero.

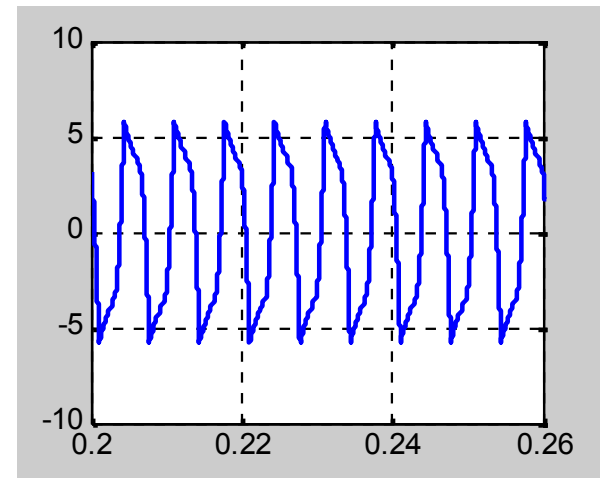

a)

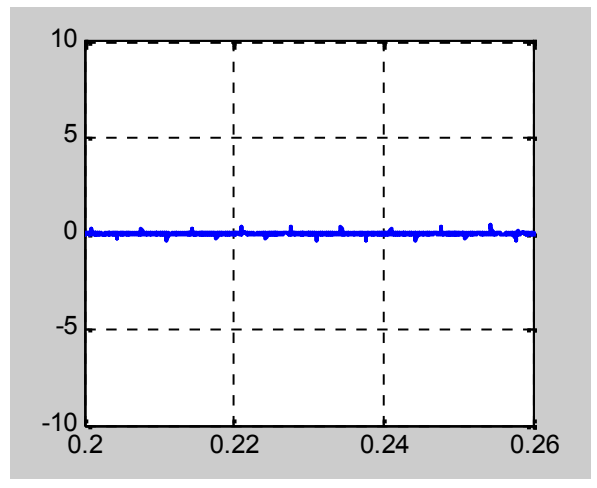

b)

Fig. 9. Neutral current waveform: a) before compensation; b) after compensation

\section{Conclusions}

In this paper, a control strategy for a hybrid filter constituted by a series active filter and a shunt passive filter was developed. This strategy was based on optimizing of power transference between source and load. By applying the Lagrange multipliers the value of the equivalent resistance of the set load-compensator was determined in order to achieve unity power factor. The control strategy was developed for a multiconductor system and after it was particularized to an active filter of three branches.

Finally, a simulation model based on Matlab-Simulink was designed and the practical results for a nonlinear load, type HCS (Harmonic Current Source), balanced and four wire were presented. The results obtained allowed the resistive behaviour of the set load-compensator to be verified. So, with the strategy proposed was possible to mitigate the source current harmonics and to compensate the load reactive power. After the compensation, the neutral current was practically zero.

\section{Acknowledgement}

This work is part of the projects "Measurement System for the Identification of Harmonic Distortion Sources and Unbalances in Public Distribution Networks", ref. DPI2010-17709, sponsored by the "Ministerio de
Economía y Competitividad” Government of Spain.

\section{References}

[1] [1] F. Z. Peng and D. J. Adams, "Harmonics sources and filtering approaches," in Proc. Industry Aplications Conference, October 1999, Vol, 1, pp. 448-455

[2] Akagi H., "Active harmonic filters," Proceedings of the IEEE, Vol. 93, Issue 12, pp. 2128-2141, Dec. 2005

[3] Peng F. Z., Akagi H., Nabae A., "A new approach to harmonic compensation in power systems-a combined system of shunt passive and series active filters," IEEE Trans. Industry Applications. Vol, 26, No. 6, pp. 983-990, Nov/Dec 1990

[4] Rivas, D.; Moran, L.; Dixon, J.W.; Espinoza, J.R.; "Improving passive filter compensation performance with active techniques", IEEE Trans. On Industrial Electronics, Vol. 50, Issue 1, pp. 161-170, Feb 2003

[5] An Luo; Zhikang Shuai; Wenji Zhu; Ruixiang Fan; Chunming Tu, "Development of hybrid active power filter based on the adaptive fuzzy dividing frequency-control method", IEEE Trans. on Power Delivery, Vol. 24, Issue 1, Jan. 2009, pp. 424-432

[6] Wang Z., Wang Q., Yao W. and Liu J., "A series active power filter adopting hybrid control approach," IEEE Trans. Power Electronics, Vol. 16, No. 3, pp. 301-310, May 2001

[7] Corasaniti, V. F.; Barbieri, M. B.; Arnera, P. L.; Valla, M. I., "Hybrid Active Filter for Reactive and Harmonics Compensation in a Distribution Network “, IEEE Trans. on Industrial Electronics, Vol. 56, Issue 3, pp. 670-677, March 2009

[8] Kim Y. S., Kim J. S. and Ko S. H., "Three-phase threewire series active power filter, which compensates for harmonics and reactive power", IEE proc. Electric. Power Applications, Vol, 151, No. 3, May 2004, pp. 276-282

[9] Herrera, R.S.; Salmerón, P.; "Instantaneous Reactive Power Theory: A Reference in the Nonlinear Loads Compensation", IEEE Trans. on Industrial Electronics, Vol. 56, Issue 6, pp. 2015-2022, June 2009

[10] Superti-Furga, G.; Todeschini, G., "Discussion on instantaneous $\mathrm{p}-\mathrm{q}$ strategies for control of active filters", IEEE Trans. on Power Electronics, Vol. 23, Issue 4, July 2008, pp. 1945-1955

[11] Salmerón P. y Litrán S. P., "A Control Strategy for Hybrid Power Filter to Compensate Four-Wires Three_Phase Systems". IEEE Transaction on Power Electronics. Vol. 25, Isue 7, pp. 1923-1931, July 2010

[12] Salmerón P. y Litrán S. P., "Improvement of the Electric Power Quality Using Series Active and Shunt Passive Filters". IEEE Transations on Power Delivery. Vol. 25, Issue 2, pp. 1058-1067, April 2010

[13] Depenbrock M., "Quantities of a multiterminal circuit determined on the basis of Kirchhoff's laws", in Proc. 4th Int. Workshop Power Definitions Measurements Under Non-Sinusoidal Conditions, Italy, pp. 29-35, 1997 